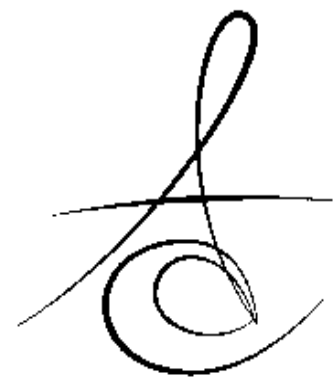

\title{
DOWN SENDROMLU ÇOCUKLARDA UYKU APNE SENDROMU VE AĞIZ DİŞ SAĞLIĞI
}

\author{
OBSTRUCTIVE SLEEP APNEA AND ORAL HEALTH IN CHILDREN \\ WITH DOWN SYNDROME
}

\author{
Arş. Gör. Dr. Müesser Ahu DURHAN*
}

Prof. Dr. İlknur TANBOĞA*

Makale Kodu/Article code: 2658

Makale Gönderilme tarihi: 11.03 .2016

Kabul Tarihi: 29.04.2016

\section{ABSTRACT}

Down Sendromu (DS) (Trizomi 21) yeni doğanın mental ve fiziksel retardasyonunu içeren yaygın kromozom anomalilerinden biridir. Down Sendrom'lu bireylerde; birçok sağlık sorunu doğrudan veya dolaylı olarak meydana gelmekte, hastanın hayat kalitesini ve yaşam süresini etkilemektedir. Bu hastalıklardan bazıları önemli boyutta medikal takip gerektirmektedir. Down Sendrom'lu çocuklarda Obstruktif Uyku Apne Sendromu önemli sağlık problemlerinden biridir. Sağlıklı çocuklarda Obstruktif Uyku Apne Sendromu görülme prevelansı \% 0,7-2 arasında değişirken, Down Sendrom'lu çocuklarda bu oran \% 31-75'lere kadar yükselmektedir Obstruktif Uyku Apne Sendromu tanısı koyulurken altın standart teşhis yöntemi uyku sırasında polisomnografi uygulamasıdır. Obstruktif Uyku Apne Sendromu'nun, Down Sendrom'lu pediatrik hasta grubunda ağız diş sağlığını nasıl etkilediğine yönelik derinlemesine çalışmalara intiyaç duyulmaktadır.

Anahtar Kelimeler: Down Sendromu, Obstruktif Uyku Apnesi

\section{ÖZET}

Down syndrome is the most common chromosomal disorder in newborns and causes delays in physical and intellectual development. Children with Down syndrome are at an increased risk for health complications beyond usual childhood illnesses and are at high risk for many disorders known to interfere with growth requring medical follow up whole life. Obstructive Sleep Apnea is one of the major health problem in children with Down Syndrome. Among the general pediatric population, up to $2-4 \%$ of children experience Obstructive Sleep Apnea. Children with Down Syndrome are at an increased risk for Obstructive Sleep Apnea when compared to children without Down Syndrome, with reported prevalence rates of $31 \pm 75 \%$ among clinic-based samples. The gold standard for diagnosis of Obstructive Sleep Apnea is overnight polysomnogrphy. Furthermore studies should be done to clarify how Obstructive Sleep Apnea affects oral health in children with Down Syndrome.

Key Words: Down's Syndrome, Obstructive Sleep Apnea

Hamileliğin 11. ve 20. haftaları arasında rutin olarak gerçekleştirilen tarama testleri, olası DS riskinin belirlenmesinde önemli yer tutmaktadır. Diğer taraftan; DS hastası çocuğun doğma riski anne yaşının ileri olması ile orantıı olarak arttığı yapılan çalışmalarla gösterilmiştir. 2,4,5

DS'li yeni doğanda; sağlıkı bebeklerle ayırıcı tanıya götüren karakteristik bazı klinik görsel bulgular mevcuttur. Ensede yelelenme denilen gevşek deri kıvrımının bulunuşu yaygın bir klinik özelliktir. Üst ve alt ekstremiteler normalden kısa, parmaklar ise kısa ve küttür. Gözler normalden küçük, gövde de meme

\footnotetext{
${ }^{*}$ Marmara Üniversitesi Diş Hekimliği Fakültesi, Pedodonti AD
}

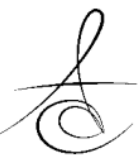


başları birbirine yakın, ayak 1. ve 2. parmaklar arasında 'Sandal Gap' adı verilen geniş bir boşluk bulunmaktadır. 3,6

DS birçok dismorfik özellikler göstermektedir. Büyüme ve gelişimde psikomotor gerilik ve mental retardardizasyon vardır. Aynı zamanda DS'li çocuklarda; sendroma eşlik eden konjenital defektler ve organik bozukluklar bulunmaktadır. ${ }^{3} \mathrm{Bu}$ hastalıklardan bazıları önemli boyutta medikal takip gerektirmektedir (Tablo I). Görülme sıklıkları göz önüne alındığında sırasıyla; kardiyovasküler sistem hastalıkları (ASD/ VSD), görme problemleri, KBB problemleri- işitme kayıpları, kronik rinit, solunum sistemi hastalıkları [obstruktif uyku apne sendromu (OUAS)], gastrointestinal sistem rahatsızlıkları (kalın barsakta konjenital defektlere bağlı problemler), hemato-onkolojik hastalıklar (sıklıkla lösemi) ve immün yetmezlik, endokrin sistem hastalıkları, ortopedik problemler ve üriner sistem hastalıklarıdır. ${ }^{3}$ Pnömoni ve konjenital kalp hastalığı; DS'li yeni doğanın en sık görülen mortalite sebeplerindendir ${ }^{3}$.

Tablo I. DS'li çocuklarda 0-18 yaş arası medikal takip planlaması (3)

\begin{tabular}{|c|c|c|c|c|}
\hline \multicolumn{5}{|c|}{ Down Sendrom'lu çocuklarda medikal takip zamanları } \\
\hline & $\begin{array}{l}0- \\
3 \\
\text { ay }\end{array}$ & $\begin{array}{l}4- \\
12 \\
\text { ay }\end{array}$ & $\begin{array}{c}\mathrm{Her} \\
\text { yll }\end{array}$ & Değerlendirme \\
\hline Genetik takip & + & & & $\begin{array}{l}\text { Bir kez, doğumdan } \\
\text { sonra }\end{array}$ \\
\hline $\begin{array}{c}\text { Kardiyak } \\
\text { Ultrasonografi (USG) }\end{array}$ & + & + & & $\begin{array}{l}\text { Kalpteki defekte bağlı } \\
\text { takip }\end{array}$ \\
\hline Göz muayene & + & + & & 3 yılda bir muayene \\
\hline İşitme & + & + & + & \\
\hline OUAS & & & + & $\begin{array}{c}\text { Polisomnografi (PSG) } \\
\text { / 3-4 yaş }\end{array}$ \\
\hline Periodontal-Dental & & & + & $\begin{array}{l}\text { Hipodonti-anadonti- } \\
\text { takip-tedavi }\end{array}$ \\
\hline Kabızlık & + & + & + & \\
\hline Çölyak hastalığı & + & & & $\begin{array}{c}\text { Her } 3 \text { yll } \\
\text { TransGlutaminaz Antikor } \\
\text { (TGA) }\end{array}$ \\
\hline Büyüme/Gelişim/Kilo & & & + & $\begin{array}{l}\text { DS Özel büyüme gelişim } \\
\text { skalası takibi }\end{array}$ \\
\hline Hematoloji & + & & + & $\begin{array}{c}\text { Doğumda, Geçici } \\
\text { Myeloproliferatif } \\
\text { Bozukluk (Transient } \\
\text { Myeloproliferative } \\
\text { Disorder -TMD) Lösemi } \\
\text { için } 5 \text { yılda bir }\end{array}$ \\
\hline Tiroid Fonksiyonları & & + & + & \\
\hline $\begin{array}{c}\text { Ortopedi/kalça } \\
\text { eklemi/diz eklemi }\end{array}$ & + & + & + & \\
\hline $\begin{array}{c}\text { Atlanto-Axial } \\
\text { İstikrarsızlık (AAI) }\end{array}$ & & & + & $\begin{array}{l}\text { Nörolojik görüntüleme, } \\
\text { entübasyon sırasında } \\
\text { takip }\end{array}$ \\
\hline Fizik Tedavi & + & + & + & İlk etkiler 0-4 yaş arası \\
\hline Dermatoloji & & & + & \\
\hline Konuşma terapisi & + & + & + & $\begin{array}{c}\text { Konuşma gelişmeye } \\
\text { başlayınca takip }\end{array}$ \\
\hline
\end{tabular}

Epidemiyoloji: Horlama; 30-40 yaş arası bireylerde erkeklerde \%10 kadınlarda \%5 olarak rapor edilirken, bu durumun yaşla doğru orantılı olarak arttığı bildirilmiş ve 50-60 yaş arası bireylerde, erkeklerde \%20 kadınlarda da \%15'lere ulaştığı bildirilmiştir. Genel popülasyonda $30-40$ yaş arası bireylerde OUAS prevelansına bakıldığında; erkeklerde \%4 kadınlarda \%2 olduğu belirlenmiştir. ${ }^{7}$ DS'li çocuklarda OUAS önemli sağlık problemlerinden biridir. Sağlıklı çocuklarda OUAS görülme prevalansı \% 0,7-2 arasında değişirken DS'li çocuklarda bu oran \% 3060 'lara kadar yükselmektedir $(8,9)$. Ek olarak OUAS teşhis edilen DS'li bireylerde, OUAS'lı sağlıklı bireylere oranla hastalığın seyri daha ağır ilerlemektedir. ${ }^{10}$

Obstruktif uyku apnesi (OUA); ilk kez 1892 yılında William Osler tarafından tarif edilmiş ancak sistematik olarak tanımlanması 1970'lerde olmuştur. Uluslararası Uyku Düzensizlikleri Sınıflamasına göre; (International Classification of Sleep Disorders-ICSD) sık tekrarlayan üst solunum yolu obstrüksiyonu ve hemoglobin saturasyonunda düşme ile karakterize uyku düzensizliği olarak tanımlanmaktadır. ${ }^{11}$

OUAS; üst hava yolunun, non-REM veya REM uykusu sırasında tıkanacak kadar daralması ile karakterizedir. Yenidoğan döneminden adolesan döneme kadar çocuklarda ve özellikle tonsil ve adenoid dokunun hızla büyüdüğü okul öncesi dönemde daha sıklıkla olmak üzere görülebilir. Sadece uyku solunum düzensizlikleri bile, çocuklarda tonsillektomi operasyonları için yeterli endikasyonu oluşturabilmektedir. Çocuklarda da OUAS tanısı; hastadan alınan detaylı anamnez ve fiziki muayene sonrası, polisomnografi ile koyulabilmektedir. ${ }^{12}$

Sağlık alanında hızla gelişen teknolojik imkanlar ve modern tıbbın hastalara daha kolay ulaşabilir olması; DS'li bireylerin yaşam sürelerine ve hayat kalitesine de artış getirmiştir. DS'li hasta gruplarında, OUAS'ın erken teşhisi ve radikal agresif tedavi sağlanması, meydana gelebilecek diğer kronik hastalıkların da önüne geçebilir. Araştırmamızda; sistematik olarak bu konuya ilişkin yapılmış dikkat çekici bilimsel araştırmaları ve gelişmeleri karşılaştırmalı olarak derlemeyi amaçladık. 


\section{TARTIŞMA}

\section{OUAS VE DS (Tablo 2)}

DS'li bireylerde; sendromdan kaynaklı fenotipik özellikler OUAS gelişimi için predispozan etki yapmaktadır. ${ }^{8,13}$. Bu durum DS'li çocuklarda; sağlıklı çocuklara oranla çok daha yüksek oranlarda OUAS'a rastlandığını göstermektedir. Yapılan radyografik değerlendirmelerde; orta yüzde ve maksillada hipoplazi tespit edilmiştir. $\mathrm{Bu}$ durumun hava yolunda tıkanıklık oluşturabileceği belirtilmiştir. ${ }^{14,15}$. Diğer OUAS'ye sebep olabilecek faktörler makroglosi, glossopitozis, tekrarlayan adenotonsiller büyüme, genişlemiş dil tonsilleri olarak gösterilmektedir. Yapılan bazı çalışmalar DS'li çocuklarda metabolik özelliklerinden dolayı obeziteye yatkınlık ve indirekt olarak yine OUAS gelişimi olduğunu göstermektedir. ${ }^{16,17}$

Tablo 2. OUAS tanısı konmuş DS'li hastalara yönelik önemli araştırmalar

\begin{tabular}{|c|c|c|c|c|}
\hline Araştırmacı/Yıl & $\begin{array}{c}\text { Çalışma } \\
\text { Tipi }\end{array}$ & $\mathbf{N}$ & $\begin{array}{c}\text { Araştır } \\
\text { ma } \\
\text { Grubu }\end{array}$ & Değerlendirme \\
\hline \begin{tabular}{|c|} 
Austeng ve ark. \\
(33) /2014
\end{tabular} & Prospektif & 29 & Pediatrik & $\begin{array}{c}\text { Çalışmaya katılan } 8 \text { yaş DS'li } \\
\text { ocukların } 2 / 3^{\prime} \text { ünde orta ya da } \\
\text { şiddetli OUAS tanısı }\end{array}$ \\
\hline $\begin{array}{c}\text { Breslin ve ark. } \\
\text { (34)/ } 2014\end{array}$ & Prospektif & 38 & Pediatrik & $\begin{array}{c}\text { OUAS olan DS'li çocuklarda } \\
\text { artmış mental retardasyon ve } \\
\text { OUAS olmayan gruba göre } \\
\text { zayıf kavrama yeteneği }\end{array}$ \\
\hline $\begin{array}{c}\text { Jheeta ve } \\
\text { ark.(35) / } 2013\end{array}$ & $\begin{array}{l}\text { Retrospek- } \\
\text { tif }\end{array}$ & 44 & Pediatrik & $\begin{array}{l}\text { Oksimetri OUAS bulunan DS'li } \\
\text { çocuklarda zayıf sensitiviteye } \\
\text { sahip }\end{array}$ \\
\hline $\begin{array}{c}\text { Shires ve ark } \\
\text { (36) / } 2010\end{array}$ & $\begin{array}{c}\text { Retrospekt } \\
\text { if }\end{array}$ & 63 & Pediatrik & $\begin{array}{c}\text { DS'li çocuklarda; BMI ve } \\
\text { OUAS arasında istatistiksel } \\
\text { olarak anlamlı ilişki }\end{array}$ \\
\hline $\begin{array}{c}\text { Shete ve } \\
\text { ark.(37) / } 2010\end{array}$ & $\begin{array}{c}\text { Retrospek- } \\
\text { tif }\end{array}$ & $\begin{aligned} 11 & =\mathrm{DS} \\
9 & =\mathrm{K}\end{aligned}$ & Pediatrik & $\begin{array}{l}\text { AT tedavisi DS'li çocuklarda } \\
\text { OUAS üzerine zayıf etkiye } \\
\text { sahip }\end{array}$ \\
\hline \begin{tabular}{|c|} 
pe Moura ve ark \\
$(38) / 2008$
\end{tabular} & Prospektif & 24 & Pediatrik & $\begin{array}{l}\text { Hızlı maksiller ekspansiyon; } \\
\text { işitme kayıpları, KBB } \\
\text { enfeksiyonları ve OUAS } \\
\text { gelişimi üzerine negatif etki }\end{array}$ \\
\hline \begin{tabular}{|c|} 
Donnelly ve ark. \\
(39)/2004
\end{tabular} & Prospektif & 27 & pediatrik & $\begin{array}{c}\text { OUAS gelişen DS'li } \\
\text { çocuklarda, makroglossi, } \\
\text { glossopitoz, büyük tonsiller }\end{array}$ \\
\hline $\begin{array}{c}\text { Dyken ve ark } \\
\text { (16) /2003 }\end{array}$ & Prospektif & 19 & pediatrik & $\begin{array}{c}\text { Araştırmaya katılan DS'li } \\
\text { çocukların \%79'unda OUAS } \\
\text { tanıSı }\end{array}$ \\
\hline $\begin{array}{c}\text { Bertrand ve ark } \\
(40) / 2003\end{array}$ & $\begin{array}{l}\text { Retrospek- } \\
\text { tif }\end{array}$ & 24 & Pediatrik & $\begin{array}{l}\text { DS'li çocuklarda solunum } \\
\text { sistemi anomalisi görülme } \\
\text { sıklığı daha fazla }\end{array}$ \\
\hline $\begin{array}{l}\text { Uong ve ark } \\
(15) / 2001\end{array}$ & Prospektif & 11 & pediatrik & $\begin{array}{c}\text { OUAS olmayan DS'li } \\
\text { socuklarda, küçük orta yüz ve } \\
\text { yumuşak doku ile çevrili üst } \\
\text { hava yolu }\end{array}$ \\
\hline
\end{tabular}

Gastroözefageal reflü; DS'li bireylerde sıklıkla görülmektedir. Reflü kaynaklı gelişen enfeksiyonlar üst solunum yolu tıkanıklıklarına sebep olur. Bu durum OUAS gelişimi için risk yaratmaktadır. ${ }^{18,19}$
Hipotiroidi olan bireylerde sağlıklı bireylere oranla daha yüksek oranda OUAS görüldüğü yapılan çalışmalarla gösterilmiştir. ${ }^{20}$ Tiroid hastalıkları DS'li bireylerde \%4-18 oranında görülmektedir. Özellikle hipotiroid hastalarının OUAS açısından risk altında olduğu göz önünde bulundurulduğunda; ileri yaşlardaki DS hastalarında OUAS gelişimi intimali ortaya çıkmaktadır. Tiroid hastalıkları üzerine yapılan çalışmalarda; tüm DS'li bireylerin 1 yaşına kadar 6 ayda bir tiroid muayenesi olması önerilmektedir.

DS'li doğan bebekler; ilerleyen yaşlarda pulmoner hipertansiyon hastası olmaya aday bireylerdir. Alveoler kapiller displazi ve artmış pulmoner damar basınc yenidoğan DS'li bebeklerde rapor edilen rahatsızlıklardır. ${ }^{21,22}$ Pulmoner hipertansiyon OUAS ile ilişkilendirilmektedir ve olası üst hava yolu obstrüksiyonlarında OUAS gelişimi söz konudur.

OUAS tanısı koyabilmek için yeterli polisomnografi değerlendirmesi yapabilmek gereklidir. DS'li, çocuklarda en uygun dönem 3-4 yaş olarak belirtilmektedir (Tablo I).

\section{OUAS VE AĞIZ DİŞ SAĞLIĞI}

Ağız ve diş sağlığı; toplumların önemli sağlık konularından biridir. Toplum içinde en yaygın görülen ağız diş sağlığı problemleri ise diş çürükleri ve periodontal hastalıklardır.

Diş çürükleri; çoğunlukla erken çocukluk döneminde başlar ve zaman içerisinde çürük yapıcı etkenler ortadan kalkmadıkça klinik olarak gözle görülür seviyeye ulaşır. Bu çürüklere başlangıç çürük lezyonları denir. Günümüzde erken dönem çürüklerine 'kavitasyon oluşmamış çürük lezyon' tanımlaması yapılmaktadır ${ }^{23}$. Diş çürüğü; diş yüzeyinde oluşan dental biyofilmin metabolik aktivitesinde dengenin bozulması neticesinde meydana geldiği yapılan moleküler mikrobiyolojik çalışmalar ile gösterilmektedir. Dengeyi bozabilecek faktörler konağa bağlı özellikler ve dış etkenler olarak sıralanabilir. DS'li hastalarda; tükürük kompozisyonu, dişlerin sürme zamanlarında değişimler, dişlerde görülebilecek yapısal farkılıklar ve ağız içindeki bazı yapılardaki şekil ve yapı anomalileri konağa ait ağız içi savunma mekanizmalarında da farklılıklar oluşturup, dental biyofilmdeki dengenin konak aleyhine bozulmasına sebep olup, diş çürüğü ve periodontal hastalıkların gelişimini hızlandırabilir. ${ }^{24}$

Tükürük; ağız diş sağlığı için çok önemli bir sıvıdır. Gece uyku esnasında tüm vücut sistemlerinde fizyolojik olarak gerçekleşen yavaşlama tükürük akış hızına da yansır. Gece oluşan fizyolojik sınırlardaki ağız

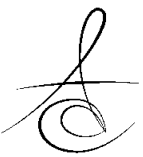


kuruluğunun sebebi budur. Ancak hastaların kronik metabolik ve sistemik bazı rahatsızlıkları ağız kuruluğunu arttırmaktadır. Sistemik bazı rahatsızlıklara ek olarak ya da bağımsız OUAS tanısı bulunan hastalarda; uykuda ağız solunumu yapılması sonucu ağız kuruluğu sıklıkla karşılaşılan şikayetlerden biridir. Ağız kuruluğu ve ağız diş sağlığı problemleri arasındaki ilişki yapılan birçok klinik ve laboratuvar çalışmalarında gösterilmiştir. ${ }^{24,25}$

Ağız diş sağlığı problemlerden bir diğeri periodontal hastalıklardır. Periodontal hastalık; periodonsiyumu oluşturan dokuların, büyük oranda da gram negatif bakteri ve spiroketlerin etken olduğu kronik bir hastalıktır. Akut atakları takiben kronik sessiz dönemler hastalığın karakteristik özelliğidir. ${ }^{26}$ Periodontal hastaIıklar; gingival inflamasyon, periodontal doku yıkımı, alveoler kemik kaybı ve en son safhada diş kayıplarına kadar ilerleyebilmektedir. Gingivitis ve periodontitisin birincil etkeni bakteriyel dental plak olmasına karşın bazı sistemik ve metabolik hastalıklarda periodontal hastalıkların şiddeti ve prognozu üzerinde etkili olmaktadır. Periodontal patojenler metabolizma içinde dolaşım sistemi ile taşınmakta ve birçok ciddi sistemik hastalıkla bağlantılı olarak da akut hastalık tablosu oluşturmaktadırlar. Bu hastalıklar sırasıyla; koroner arter hastalıkları, diyabet, inme (felç), aterosklerozis, romatoit artrit, prematüre doğum ve son dönemlerde sıkIıkla rastlanılan OUAS tablosudur. Çeşitli ülkelerde; periodontal sağlık alanında yapılan epidemiyolojik çaIışmalar incelendiğinde; ortalama olarak toplum- larda; $\% 45$ oranında kronik, \%8-9 oranında ciddi ve \%30 dan \%8'lere kadar değişen oranlarda da orta şiddette periodontal hastalık olduğu gösterilmiştir. Bu oranları belirleyen risk faktörleri; yaş, cinsiyet, ırk, obezite, alkol bağımlılı̆ı, ve stres olarak sıralanmaktadır. Diğer taraftan; kötü oral hijyen, diyabet, sigara tüketimi ve genetik de oldukça etkili diğer faktörler arasında yer almaktadır. ${ }^{27,28}$

OUAS tanısı olan hastalarda; inflamatuar sitokin seviyelerinde artış gözlenmektedir. Bunlar artış sırası göz önüne alındığında; interlökin-1B, interlökin-6, tumor nekrozis faktör-alfa, C-reaktif protein ve diğer sitokinler ${ }^{29,3}$ olarak belirlenmiştir. Yapılan bilimsel çalışmalara baktığımızda elde edilen sonuçlar; OUAS ve ileri düzey periodontal hastalıkların patogenezinde; inflamatuar medyatörlerin benzer mekanizma ile yakın risk oluşturduğunu göstermektedir. ${ }^{31}$

Tablo 3 verileri incelendiğinde; OUAS tanısı konmuş yetişkin hastalarda ağız diş sağlığına yönelik araştırmaların daha yoğun olduğunu görülmektedir. OUAS tanısı konmuş DS'li pediatrik hastalarda ağız diş sağlığına yönelik araştırmalar az olmakla birlikte; yapılan bir çalışmada; dental plak oluşumu, gingival inflamasyon ve diş çürüğü görülme sıklığı OUAS olmayan hastalara göre daha düşük, ağız hijyeni ise daha iyi ve kabul edilebilir sınırlarda bulunmuştur. ${ }^{32}$ OUAS'ın, DS'li pediatrik hasta grubunda ağız diş sağlığını nasıl etkilediğine yönelik derinlemesine çalışmalara intiyaç duyulmaktadır.

Tablo 3. OUAS ve Periodontal hastalık arasındaki ilişkiyi gösteren yapılmış bilimsel çalışmalar

\begin{tabular}{|c|c|c|c|c|c|}
\hline $\begin{array}{c}\text { Araştırmacı/ } \\
\text { YIl }\end{array}$ & $\begin{array}{c}\text { Çalış̧ma } \\
\text { Tipi }\end{array}$ & $\mathrm{N}$ & $\begin{array}{c}\text { Araştı } \\
\text { rma } \\
\text { Grubu }\end{array}$ & $\begin{array}{c}\text { OUAS } \\
\text { Teşhis } \\
\text { Yöntemi }\end{array}$ & Değerlendirme \\
\hline $\begin{array}{c}\text { Al-Hammad } \\
\text { ve ark } 2015 \\
(32)\end{array}$ & $\begin{array}{l}\text { Vaka- } \\
\text { kontrol }\end{array}$ & $\begin{array}{c}\mathrm{n}=30 \\
\text { (çalışma) } \\
\mathrm{n}=30 \\
\text { (kontrol) } \\
\text { yaş: } 3-8\end{array}$ & $\begin{array}{l}\text { Pedi- } \\
\text { atrik }\end{array}$ & $\begin{array}{c}\text { Polisomo- } \\
\text { nografi }\end{array}$ & $\begin{array}{c}\text { OUAS tanıSı } \\
\text { konmuş } \\
\text { çocuklarda, } \\
\text { sağlıklı çocuklara } \\
\text { oranla daha iyi } \\
\text { ağız hijyeni ve } \\
\text { daha düşük çürük } \\
\text { ve gingival } \\
\text { inflamasyon } \\
\text { görülmüştür. }\end{array}$ \\
\hline $\begin{array}{l}\text { Loke ve ark. } \\
2015(41)\end{array}$ & $\begin{array}{l}\text { Prospektif } \\
\text { Vaka- } \\
\text { kontrol }\end{array}$ & $\begin{array}{c}n=100 \\
\text { yaş:28-79 }\end{array}$ & $\begin{array}{l}\text { Yetis- } \\
\text { kin }\end{array}$ & $\begin{array}{c}\text { Polismo- } \\
\text { nografi }\end{array}$ & $\begin{array}{l}\text { OUAS ağız diş } \\
\text { sağıığını negatif } \\
\text { olarak } \\
\text { etkilememekte- } \\
\text { dir. }\end{array}$ \\
\hline $\begin{array}{c}\text { Nizam ve ark. } \\
2014(42)\end{array}$ & $\begin{array}{l}\text { Vaka- } \\
\text { kontrol }\end{array}$ & $\begin{array}{c}n=52 \\
\text { yaş:21-64 }\end{array}$ & $\begin{array}{l}\text { Yetiş- } \\
\text { kin }\end{array}$ & $\begin{array}{c}\text { Polismo- } \\
\text { nografi }\end{array}$ & $\begin{array}{c}\text { Araştırmacıya } \\
\text { göre, OUAS } \\
\text { şiddetine bağımlı } \\
\text { olarak; hastalarda } \\
\text { tükürük IL-6 ve } \\
\text { IL-33 seviyesi } \\
\text { artış yönünde } \\
\text { etkilenmektedir. }\end{array}$ \\
\hline $\begin{array}{l}\text { Seo ve ark } \\
2013 \text { (43) }\end{array}$ & Kesitsel & $\begin{array}{c}\mathrm{n}=687 \\
\text { (çalışma) } \\
\text { yaş: } \\
55.85 \pm 6.6\end{array}$ & $\begin{array}{l}\text { Yetiş } \\
\text { kin }\end{array}$ & $\begin{array}{c}\text { Polisom- } \\
\text { nografi ve } \\
\text { evde uyku } \\
\text { testi }\end{array}$ & $\begin{array}{c}\text { Araştırmacilara } \\
\text { göre; OUAS ve } \\
\text { periodontitis } \\
\text { arasında belirgin } \\
\text { bir ilişki } \\
\text { bulunmaktadır. }\end{array}$ \\
\hline $\begin{array}{c}\text { Acar ve ark } \\
2015 \text { (44) }\end{array}$ & $\begin{array}{l}\text { Vaka- } \\
\text { kontrol }\end{array}$ & $\begin{array}{c}\mathrm{n}=250 \\
\text { (çalsssma) } \\
\mathrm{n}=41(\text { kontrol) } \\
\text { yaş:50.8 } \\
4 \\
4\end{array}$ & $\begin{array}{l}\text { Yetiş- } \\
\text { kin }\end{array}$ & $\begin{array}{c}\text { Polisom- } \\
\text { nografi }\end{array}$ & $\begin{array}{l}\text { OUAS ağız diş } \\
\text { sağılığını olumsuz } \\
\text { etkilememek- } \\
\text { tedir. }\end{array}$ \\
\hline $\begin{array}{l}\text { Keller ve ark } \\
2013 \text { (45) }\end{array}$ & $\begin{array}{c}\text { Topluma } \\
\text { dayalı vaka } \\
\text { kontrol }\end{array}$ & 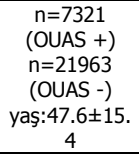 & $\begin{array}{c}\text { Yetişk } \\
\text { in }\end{array}$ & $\begin{array}{c}\text { Polisom- } \\
\text { nografi }\end{array}$ & $\begin{array}{l}\text { OUAS ve kronik } \\
\text { periodontitis } \\
\text { arasında ilişki } \\
\text { vardır. }\end{array}$ \\
\hline $\begin{array}{c}\text { Gunaranam } \\
\text { ve ark } 2009 \\
\text { (31) }\end{array}$ & Kesitsel & $\begin{array}{c}\mathrm{n}=66 \\
\text { yaş: } \\
54.9 \pm 12.8\end{array}$ & $\begin{array}{l}\text { Yetiş- } \\
\text { kin }\end{array}$ & $\begin{array}{c}\text { Polisom- } \\
\text { nografi }\end{array}$ & $\begin{array}{c}\text { Aratırmacılara } \\
\text { göre; OUAS tanısı } \\
\text { konmuş } \\
\text { hastalarda } \\
\text { periodontal } \\
\text { hastalık } \\
\text { olmayanlara } \\
\text { oranla daha } \\
\text { yüksek oranda } \\
\text { gözlenmiş. }\end{array}$ \\
\hline
\end{tabular}

\section{KAYNAKLAR}

1. Andersson EM, Axelsson $\mathrm{S}$, Austeng ME, Overland $B$, Valen IE, Jensen TA, et al. Bilateral hypodontia is more common than unilateral hypodontia in 
children with Down syndrome: a prospective population-based study. Eur J Orthod. 2014;36:414-8.

2. Acikbas I, Tomatir AG, Akdag B, Koksal A. Retrospective analysis of live birth prevalence of children with Down syndrome in Denizli, Turkey. Genet Mol Res. 2012;11:4640-5.

3. Weijerman ME, de Winter JP. Clinical practice. The care of children with Down syndrome. Eur J Pediatr. 2010;169:1445-52.

4. Ocak Z, Ozlu T, Yazicioglu HF, Ozyurt O, Aygun M. Clinical and cytogenetic results of a large series of amniocentesis cases from Turkey: report of 6124 cases. J Obstet Gynaecol Res. 2014;40:139-46.

5. Danisman N, Kahyaoglu S, Celen S, Kahyaoglu I, Candemir Z, Yesilyurt A, et al. A retrospective analysis of amniocenteses performed for advanced maternal age and various other indications in Turkish women. J Matern Fetal Neonatal Med. 2013;26:242-5.

6. Weijerman $M E$, van Furth $A M$, Vonk Noordegraaf A, van Wouwe JP, Broers CJ, Gemke RJ. Prevalence, neonatal characteristics, and first-year mortality of Down syndrome: a national study. J Pediatr. 2008;152:15-9.

7. Ahmad NE, Sanders AE, Sheats R, Brame JL, Essick GK. Obstructive sleep apnea in association with periodontitis: a case-control study. J Dent Hyg. 2013;87:188-99.

8. Lal C, White DR, Joseph JE, van Bakergem K, LaRosa A. Sleep-disordered breathing in Down syndrome. Chest. 2015;147:570-9.

9. Shott SR, Amin R, Chini B, Heubi C, Hotze S, Akers R. Obstructive sleep apnea: Should all children with Down syndrome be tested? Arch Otolaryngol Head Neck Surg. 2006;132:432-6.

10. Trois MS, Capone GT, Lutz JA, Melendres MC, Schwartz AR, Collop NA, et al. Obstructive sleep apnea in adults with Down syndrome. J Clin Sleep Med. 2009;5:317-23.

11. Balbani AP, Weber SA, Montovani JC. Update in obstructive sleep apnea syndrome in children. Braz J Otorhinolaryngol. 2005;71:74-80.

12. Cote V, Ruiz AG, Perkins J, Sillau S, Friedman NR. Characteristics of children under 2 years of age undergoing tonsillectomy for upper airway obstruction. Int J Pediatr Otorhinolaryngol 2015;79:903-8.

13. Goffinski A, Stanley MA, Shepherd N, Duvall N, Jenkinson SB, Davis $C$, et al. Obstructive sleep apnea in young infants with Down syndrome evaluated in a Down syndrome specialty clinic. Am
J Med Genet A. 2015;167:324-30.

14. Guimaraes CV, Donnelly LF, Shott SR, Amin RS, Kalra M. Relative rather than absolute macroglossia in patients with Down syndrome: implications for treatment of obstructive sleep apnea. Pediatr Radiol. 2008;38:1062-7.

15. Uong EC, McDonough JM, Tayag-Kier CE, Zhao H, Haselgrove J, Mahboubi $S$, et al. Magnetic resonance imaging of the upper airway in children with Down syndrome. Am J Respir Crit Care Med. 2001;163:731-6.

16. Dyken ME, Lin-Dyken DC, Poulton S, Zimmerman MB, Sedars E. Prospective polysomnographic analysis of obstructive sleep apnea in down syndrome. Arch Pediatr Adolesc Med. 2003; 157:655-60.

17. Shott SR. Down syndrome: common otolaryngologic manifestations. Am J Med Genet C Semin Med Genet. 2006;142:131-40.

18. Macchini F, Leva E, Torricelli M, Valade A. Treating acid reflux disease in patients with Down syndrome: pharmacological and physiological approaches. Clin Exp Gastroenterol. 2011;4:19-22.

19. May JG, Shah P, Lemonnier L, Bhatti G, Koscica J, Coticchia JM. Systematic review of endoscopic airway findings in children with gastroesophageal reflux disease. Ann Otol Rhinol Laryngol. 2011; 120: 116-22.

20. Attal P, Chanson P. Endocrine aspects of obstructive sleep apnea. J Clin Endocrinol Metab. 2010; 95:483-95.

21. Galambos C. Alveolar Capillary Dysplasia in a Patient with Down's Syndrome. Pediatr Dev Pathol. 2006; 9:254-5

22. Shehata BM, A.bramowsky CR. Alveolar capillary dysplasia in an infant with trisomy 21 . Pediatr Dev Pathol. 2005;8:696-700.

23. Kuhnisch J, Ekstrand KR, Pretty I, Twetman S, van Loveren C, Gizani S, et al. Best clinical practice guidance for management of early caries lesions in children and young adults: an EAPD policy document. Eur Arch Paediatr Dent. 2016;17:3-12.

24. Areias C, Sampaio-Maia B, Pereira Mde L, Azevedo A, Melo P, Andrade $C$, et al. Reduced salivary flow and colonization by mutans streptococci in children with Down syndrome. Clinics (Sao Paulo). 2012;67:1007-11.

25. Rosenberg SS, Kumar S, Williams NJ. Attention deficit/hyperactivity disorder medication and dental caries in children. J Dent Hyg. 2014;88: 342-7. 
26. Al-Jewair TS, Al-Jasser R, Almas K. Periodontitis and obstructive sleep apnea's bidirectional relationship: a systematic review and metaanalysis. Sleep Breath. 2015;19:1111-20.

27. Gorman A, Kaye EK, Apovian C, Fung TT, Nunn M, Garcia RI. Overweight and obesity predict time to periodontal disease progression in men. J Clin Periodontol. 2012;39:107-14.

28. Kornman KS, Crane A, Wang HY, di Giovine FS, Newman MG, Pirk FW, et al. The interleukin-1 genotype as a severity factor in adult periodontal disease. J Clin Periodontol. 1997;24:72-7.

29. Minoguchi $K$, Tazaki T, Yokoe T, Minoguchi $H$, Watanabe $Y$, Yamamoto $M$, et al. Elevated production of tumor necrosis factor-alpha by monocytes in patients with obstructive sleep apnea syndrome. Chest. 2004;126:1473-9.

30. Yokoe T, Minoguchi K, Matsuo $\mathrm{H}$, Oda $\mathrm{N}$, Minoguchi $H$, Yoshino $G$, et al. Elevated levels of $C$ reactive protein and interleukin- 6 in patients with obstructive sleep apnea syndrome are decreased by nasal continuous positive airway pressure. Circulation. 2003;107:1129-34.

31. Gunaratnam K, Taylor B, Curtis B, Cistulli P. Obstructive sleep apnoea and periodontitis: a novel association? Sleep Breath. 2009;13:233-9.

32. Al-Hammad NS, Hakeem LA, Salama FS. Oral health status of children with obstructive sleep apnea and snoring. Pediatr Dent. 2015;37:35-9.

33. Austeng ME, Overland B, Kvaerner KJ, Andersson EM, Axelsson S, Abdelnoor $M$, et al. Obstructive sleep apnea in younger school children with Down syndrome. Int J Pediatr Otorhinolaryngol. 2014;78:1026-9.

34. Breslin J, Spano G, Bootzin R, Anand P, Nadel L, Edgin J. Obstructive sleep apnea syndrome and cognition in Down syndrome. Dev Med Child Neurol. 2014;56:657-64.

35. Jheeta S, McGowan M, Hadjikoumi I. Is oximetry an effective screening tool for obstructive sleep apnoea in children with Down syndrome? Arch Dis Child 2013;98:164.

36. Shires CB, Anold SL, Schoumacher RA, Dehoff GW, Donepudi SK, Stocks RM. Body mass index as an indicator of obstructive sleep apnea in pediatric Down syndrome. Int J Pediatr Otorhinolaryngol. 2010;74:768-72.

37. Shete MM, Stocks RM, Sebelik ME, Schoumacher RA. Effects of adeno-tonsillectomy on polysomnography patterns in Down syndrome children with obstructive sleep apnea: a comparative study with children without Down syndrome. Int J Pediatr Otorhinolaryngol. 2010;74:241-4.

38. de Moura CP, Andrade D, Cunha LM, Tavares MJ, Cunha MJ, Vaz $P$, et al. Down syndrome: otolaryngological effects of rapid maxillary expansion. J Laryngol Otol. 2008;122:1318-24.

39. Donnelly LF, Shott SR, LaRose CR, Chini BA, Amin RS. Causes of persistent obstructive sleep apnea despite previous tonsillectomy and adenoidectomy in children with down syndrome as depicted on static and dynamic cine MRI. AJR Am J Roentgenol. 2004;183:175-81.

40. Bertrand P, Navarro H, Caussade S, Holmgren N, Sanchez I. Airway anomalies in children with Down syndrome: endoscopic findings. Pediatr Pulmonol. 2003;36:137-41.

41. Loke $W$, Girvan $T$, Ingmundson $P$, Verrett $R$, Schoolfield J, Mealey BL. Investigating the association between obstructive sleep apnea and periodontitis. J Periodontol. 2015;86:232-43.

42. Nizam N, Basoglu OK, Tasbakan MS, Nalbantsoy A, Buduneli N. Salivary cytokines and the association between obstructive sleep apnea syndrome and periodontal disease. J Periodontol 2014; 85:251-8.

43. Seo WH, Cho ER, Thomas RJ, An SY, Ryu JJ, Kim $\mathrm{H}$, et al. The association between periodontitis and obstructive sleep apnea: a preliminary study. J Periodontal Res. 2013;48:500-6.

44. Acar M, Turkcan I, Ozdas T, Bal C, Cingi C. Obstructive sleep apnoea syndrome does not negatively affect oral and dental health. J Laryngol Otol. 2015;129:68-72.

45. Keller JJ, Wu CS, Chen YH, Lin HC. Association between obstructive sleep apnoea and chronic periodontitis: a population-based study. J Clin Periodontol. 2013;40:111-7.

\author{
Yazışma Adresi \\ Prof Dr İlknur TANBOĞA \\ Marmara Üniversitesi \\ Diş Hekimliği Fakültesi Pedodonti A.D., 34854 \\ Başıbüyük Yerleşkesi Maltepe /İstanbul \\ 02164210613 \\ e-mail: ahudurhan@hotmail.com
}

